\title{
Impact of Low Grade Periventricular-Intraventricular Hemor- rhage on Neurodevelopmental Outcome of Preterm Infants
}

\author{
Atef Alshafei, MRCPCH. MSc* \\ Neonatology, Pediatric Department, Dubai Hospital, Dubai, United Arab Emirates \\ *Corresponding author: Atef Alshafei, MRCPCH. MSC, Neonatology NICU, Pediatric Department, \\ PO box 7272, Dubai Hospital, Dubai, United Arab Emirates, Tel: 00971561924270
}

\begin{abstract}
Improvement of neonatal intensive care in the modern era has greatly changed the demographic image with evolving new generation of extreme preterm survivors. And indeed, evolving new co-morbidities that influence the short and long-term outcomes of these infants.

Periventricular-Intraventricular hemorrhage (PVH-IVH) is a significant health problem affecting the brain structures in a critical stage of development in preterm infants. Although the incidence has declined since the 80's of the last century, $\mathrm{PVH}-\mathrm{IVH}$ continued to be a costly co-morbidity in this subset of infants. Life-long neurological sequelae especially cerebral palsy, seizures, coordination disorders, and developmental delay are major concern to health care givers and represent significant economic and social burden to the family. This review offers an update on the pathogenesis, diagnostic neuroimaging modalities, and the long-term neurodevelopmental outcomes of mild grades $\mathrm{PVH}-\mathrm{IVH}$ in preterm survivors.
\end{abstract}

\section{Keywords}

Cerebral palsy, Intraventricular hemorrhage, Neurodevelopmental outcomes, Preterm infant

\section{Abbreviations}

PVH-IVH: Periventricular Hemorrhage-Intraventricular Hemorrhage; CP: Cerebral Palsy; WMI: White Matter Injury; cUS: Cranial Ultrasound; MRI: Magnetic Resonance Image

\section{Introduction}

Intraventricular hemorrhage is considered as the most common central nervous system bleeding in preterm infants particularly very low birth weight neonates (VLBW) weighing less than $1500 \mathrm{~g}$ with gestational age less than 28 weeks. The incidence of PVH-IVH is inversely related to the gestational age of preterm infants being highest among extreme premature infants with extreme low birth weights [1]. It is estimated that the incidence of $\mathrm{PVH}-\mathrm{IVH}$ reach up to $30 \%$ in infants born between the $23^{\text {rd }}$ and $26^{\text {th }}$ week of gestation [2]. Bleeding in brain ventricles occurs because blood vessels in the germinal matrix are quite fragile and susceptible to different noxious stimuli that eventually lead to rupture and bleeding [3]. Cranial ultrasonography remains the main diagnostic tool of IVH despite the limited ability to define white matter injuries and cerebellar lesions which are important determinants of the future neurocognitive performance among IVH survivors. The pathophysiology, classifications, common risk factors and clinical presentation of PVH-IVH in preterm infants will be reviewed. Furthermore, this review aims to directly assess the current neuroimaging techniques and how the lower grades IVH impact the future neurocognitive outcomes of IVH survivors.

\section{Pathophysiology and Classification}

PVH-IVH typically originates at the germinal matrix which is a highly cellular structure consisting of neuronal and glial precursor cells. It has extremely fragile blood vessels and a free communication between the capillary network and the venous system located mainly between thalamus and caudate nucleus at the level of foramen of Monro. Impaired cerebral autoregulation in preterm infants represents the second major determining factor in $\mathrm{PVH}-\mathrm{IVH}$ pathogenesis. Fluctuation in systemic blood pressure is associated with significant similar swings in cerebral blood flow velocities leading to damage of the vulnerable fragile capillary network and bleeding in the germinal matrix when cerebral

Citation: Alshafei A (2020) Impact of Low Grade Periventricular-Intraventricular Hemorrhage on Neurodevelopmental Outcome of Preterm Infants. Int J Pediatr Res 6:060. doi.org/10.23937/24695769/1510060

Accepted: April 07, 2020: Published: April 09, 2020

Copyright: (c) 2020 Alshafei A. This is an open-access article distributed under the terms of the Creative Commons Attribution License, which permits unrestricted use, distribution, and reproduction in any medium, provided the original author and source are credited. 
Table 1: Comparison between Papile and Volpe Grading classification of PVH-IVH.

\begin{tabular}{|c|c|c|c|}
\hline Papile criteria & Description & Volpe criteria & Description \\
\hline Grade I & $\begin{array}{l}\text { Hemorrhage limited to } \\
\text { germinal matrix }\end{array}$ & Grade I & $\begin{array}{l}\text { Blood in the germinal matrix with } \\
\text { or without IVH less than } 10 \% \text { of } \\
\text { ventricular space }\end{array}$ \\
\hline Grade II & $\begin{array}{l}\text { Blood noted within the } \\
\text { ventricular system but not } \\
\text { distending it }\end{array}$ & Grade II & $\begin{array}{l}\text { IVH occupying } 10-50 \% \text { of } \\
\text { ventricular space on parasagittal } \\
\text { view }\end{array}$ \\
\hline Grade III & $\begin{array}{l}\text { Blood in the ventricles with } \\
\text { distension of the ventricles }\end{array}$ & Grade III & $\begin{array}{l}\text { IVH occupying greater than } 50 \% \text { of } \\
\text { ventricle with or without ventricular } \\
\text { echo-densities }\end{array}$ \\
\hline Grade IV & $\begin{array}{l}\text { Intraventricular hemorrhage } \\
\text { with parenchymal extension }\end{array}$ & $\begin{array}{l}\text { Separate notation of other } \\
\text { findings }\end{array}$ & $\begin{array}{l}\text { Periventricular hemorrhagic } \\
\text { infarction }\end{array}$ \\
\hline
\end{tabular}

Table 2: Schematic diagram of the common risk factors of $\mathrm{PVH}-\mathrm{IVH}$.

\begin{tabular}{|l|l|l|}
\hline Antenatal factors & Delivery and labour & Neonatal factors \\
\hline 1-Infection & 1-Maternal demography, transport, and & 1-Prematurity \\
2-Pre-eclampsia & health care. & 2-Neonatal transport. \\
3-Drugs: Lack of corticosteroids & 2-Vaginal delivery & 3-RDS, mechanical ventilation. \\
4-Perinatal asphyxia & 3-Early cord clamping & 4-Resuscitation \\
5-Genetic factors & 4-Intrapartum asphyxia & 5-Hypotension and Hypovolemia \\
& & 6-Anemia \\
& & 7-PDA \\
& & 8-Pneumothorax \\
& & 9-Coagulopathy \\
& & 10-Sepsis \\
& & 11-Acidosis \\
& & 12-Hypoxia \\
& & 13-Hypothermia \\
\hline
\end{tabular}

PDA: Patent Ductus Arteriosus; RDS: Respiratory Distress Syndrome.

autoregulation is impaired. A comparison of the anatomical classification systems of PVH-IVH by Papile and Volpe is given in Table 1. Grades I-II IVH are considered as mild grades while grades III-IV are labelled as severe IVH $[4,5]$.

\section{Pathogenesis}

The pathogenesis of PVH-IVH is multifactorial and complex. The Table 2 summaries the different risk factors for intraventricular hemorrhage in preterm infants. The large capillary network in the geminal matrix is very delicate and thin walled and lacks adequate anatomical support. It is highly sensitive to hypoxic insults and increased venous pressure, with increased permeability and easy bleeding in the sub-ependymal region that can progressively extend to the ventricular system [6]. The fragility of the matrix microvasculature comes from: 1) Insufficiency of pericytes, which are the mural cells or the vascular endothelial smooth muscle cells; 2 ) Fibronectin deficiency in the basal lamina: Fibronectin molecules beside collagen, heparan and laminin are important components of basal lamina which is an essential structure of the blood brain barrier (BBB); 3) Glial fibrillary acidic protein (GFAP) deficiency in astrocytes: GFAP is a nanofilament protein in the astrocytes pro- cesses (end-feet) that extend around blood vessels to provide structural and haemostatic support to the BBB.

\section{Clinical Presentation and Diagnostic Neuroim- aging}

Most cases of PVH-IVH in preterm infants take place in the first postnatal week although the occurrence maybe much later. The presentation of hemorrhage can be either a catastrophic event with collapse and neurologic deterioration that progresses within hours to respiratory depression and coma [7]. The second presentation often follows a subtler course with nonspecific easily overlooked signs such as hypotonia, pallor, respiratory distress and often diagnosed on routine cranial ultrasound examinations [8].

\section{Neuroimaging}

\section{Real time cranial ultrasound (CUS)}

It is the most commonly used diagnostic tool with high sensitivity (96\%) and specificity (94\%). It is cheap, non-invasive and allows several bed side brain scans with comfort $[9,10]$. It is the method of choice to screen for and follow up the progression of PVH-IVH in preterm infants especially extremely low birth weight infants 


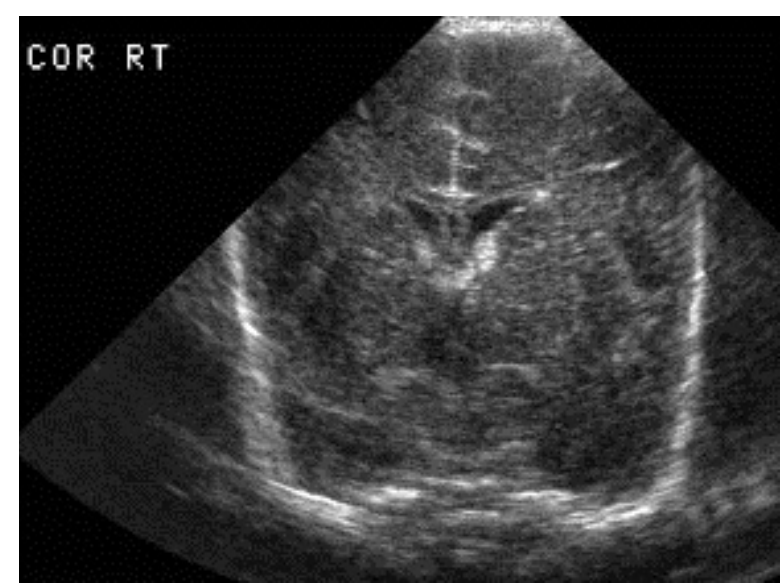

A

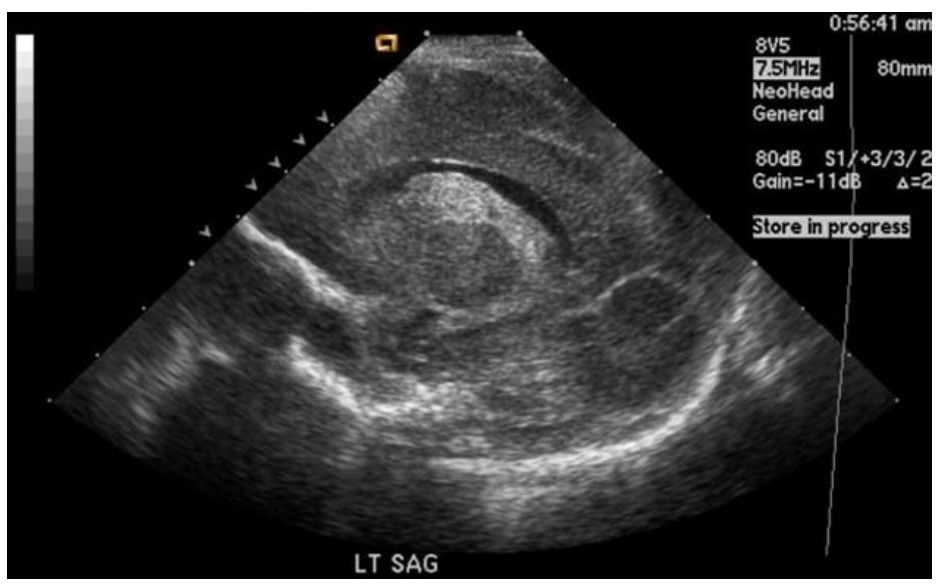

B

Figure 1: A) Grade I sub-ependymal hemorrhage in a 5- day old premature infant, Coronal view ultrasound; B) Grade II PVHIVH in sagittal view.

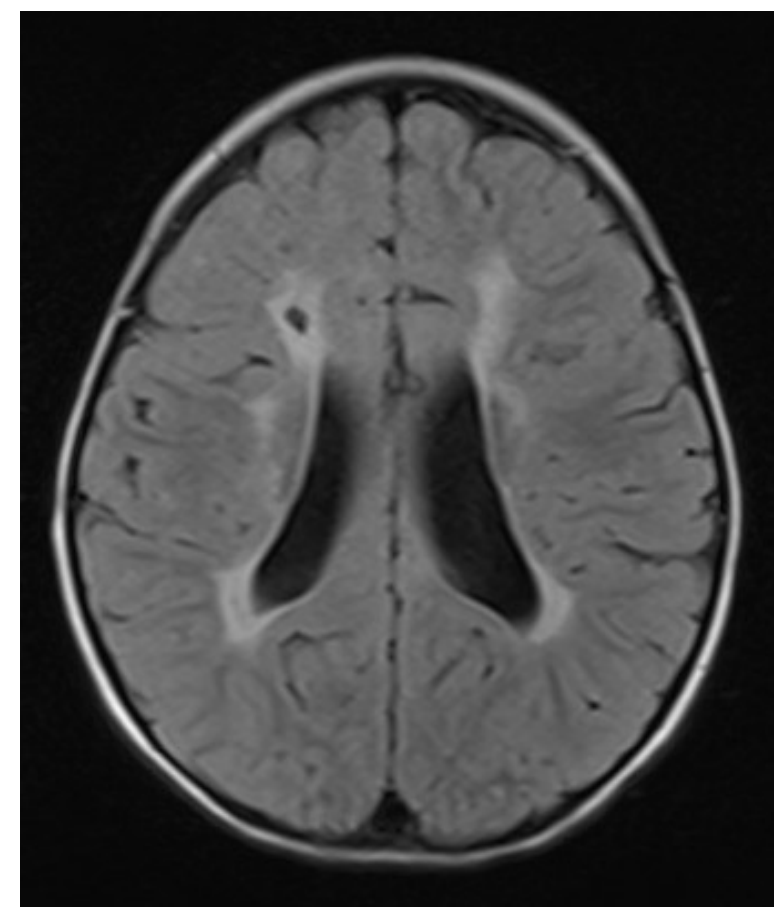

Figure 2: Brain MRI, Periventricular leukomalacia.

less than $1000 \mathrm{~g}$ (Figure 1). Cranial ultrasonography limitations include operator dependency, scanning difficulty of the posterior cranial fossa and subtle diffuse white matter abnormalities, and the limited prediction of the outcome in the high-risk preterm infants [11].

\section{Conventional brain Magnetic resonance imaging (MRI)}

It is a powerful non-ionising tool that can effectively diagnose subtle brain lesions in preterm infants particularly diffuse non-cystic PVL, infarctions, and posterior fossa abnormalities (Figure 2). However, the need for transport to MRI scan, the long-time of examination, and the other logistic issues has limited its utilisation in neonatal units [12]. Unfortunately, the current neuroimaging tools including cUS and even the conventional
$\mathrm{MRI}$, cannot correlate accurately with the microscopic subtle neuropathological diagnoses like gliosis and neuronal-axonal injury which need micron and not millimetre working MRI resolution [13].

\section{Quantitative brain MRI}

Through computational analysis of brain structure, connectivity, and function; quantitative brain MRI can analyse metabolic changes associating subtle perinatal brain injuries. Thus, with clinical correlation, it may establish cognitive and neurodevelopmental prognosis in preterm infants with PVH-IVH at earlier ages [14,15]. The reduction in cerebral, cerebellar, and basal ganglia volumes in preterm infants with white matter injury is well documented in previous studies and can be detected by the volumetric brain MRI imaging at term equivalent age $[16,17]$.

\section{Diffusion tensor imaging (DTI)}

It is an advanced computational MRI technique assessing changes in water molecule diffusion parameters in the brain tissues which are early indicators of neonatal brain damage (Figure 3). With assessing and quantifying the early WM microstructures integrity, it can predict future cognitive and motor outcomes of IVH survivors $[18,19]$.

\section{Complications and Outcome}

It is estimated that $35-40 \%$ of infants with IVH will suffer from periventricular leukomalacia (PVL), hydrocephalus, neurocognitive delay, cerebral palsy (CP), or seizures [20]. A spectrum of WMI has expanded greatly after brain MRI's widespread use and included unrecognised lesions commonly missed by cUS screening. PVL with diffuse necrosis and gliosis is commonly associated with PVH-IVH. IVH could be the pathogenetic mechanism for the development of PVL and other mixed patterns of encephalopathy of prematurity [21]. These complications worsen with increased severity of PVHIVH and decreased gestational age. Mortality rate is di- 
A Patient 1
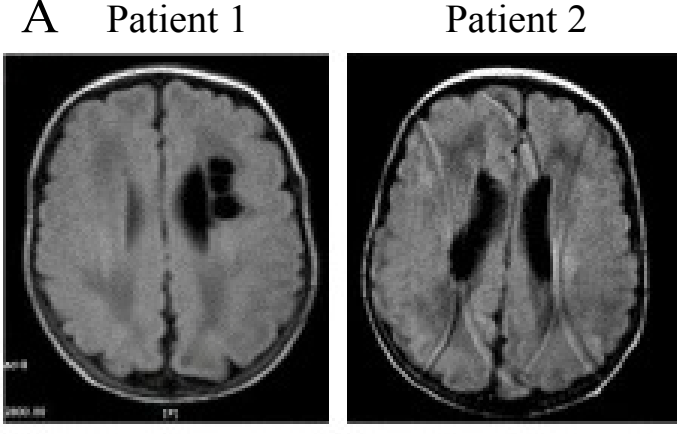

Patient 3

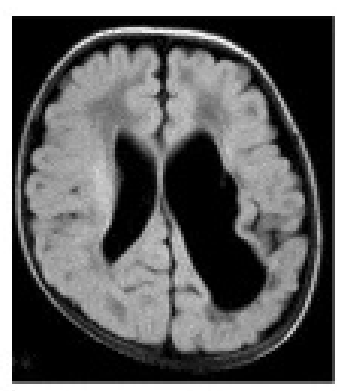

Patient 4

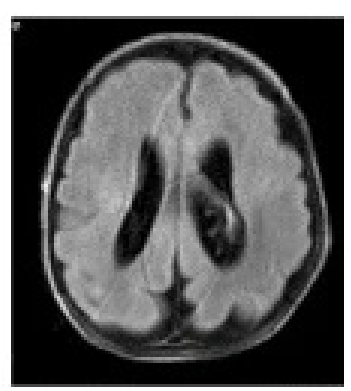

Patient 5

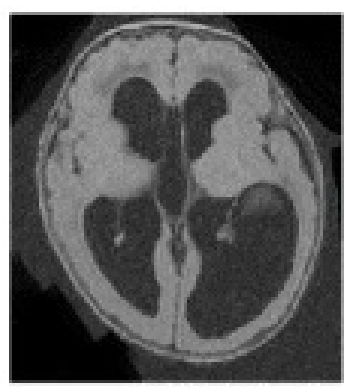

B
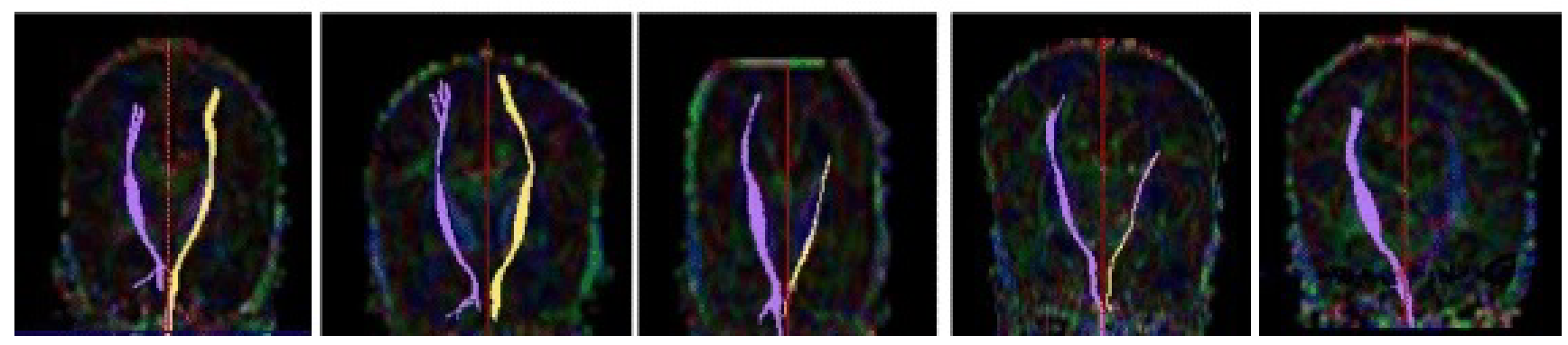

Figure 3: Diffusion tensor imaging (DTI). Preterm infants with WMI and CP. A) Axial images on T2 flair; B) DTI showing the trajectory of motor fibres normally in patients 1,2 and absent in patient 5 on left side.

Table 3: Details of search strategy.

\begin{tabular}{|l|l|l|}
\hline Search terms/Key words & Database used & Exclusion criteria \\
\hline Preterm, premature & Cochrane review & Other brain lesions as PVL, PHVD \\
Infant, Child & Pub med & IVH in term infants \\
Intraventricular hemorrhage & Ovid & Expert opinion, case reports, \\
Periventricular hemorrhage & Up to date & \\
PVH-IVH & EBSCO & \\
Intracranial bleeding & Google Scholar & \\
Neurodevelopment & Web of Science \\
Neurodevelopmental impairment & TRIP & \\
Cognitive function & EMBASE & \\
Intellectual function & & \\
Cerebral palsy & & \\
\hline
\end{tabular}

PVL: Periventricular Leukomalacia; PHVD: Post Hemorrhagic Ventricular Dilatation; IVH: Intraventricular Hemorrhage.

rectly proportional to the severity of IVH. Mortality rate reaches 4-10 percent in lower grades $\mathrm{PVH}-\mathrm{IVH}$, and up to $30 \%-40 \%$ for grades III and IV [22].

\section{Neurodevelopmental Outcomes}

The prediction of neurodevelopmental outcome in preterm infants with $\mathrm{PVH}-\mathrm{IVH}$ is dependent on three main criteria: 1) Clinical assessment; 2) Neuroimaging evaluation; 3) Neuropathological findings. Neurodevelopmental outcome is a composite term, and assessment typically includes neurologic, sensory, and cognitive evaluation preferably by an experienced researcher at 18-24 months corrected age. Bayley Scales for Infant and Toddler Development is a reliable tool for developmental assessment comparing results to a standardized norm [23]. In this scale, fine and gross motor development, cognitive development, and receptive and expressive language are assessed and scaled to a mean of
100 with a standard deviation (SD) of 15 . A score less than 85 is classified as "at risk" of developmental delay and a score of less than 70 on any of the subscales is considered "delayed" [24]. Other tools involving parents as an active role player in neurodevelopmental assessment team are gaining popularity such as The Ages and Stages Questionnaire (ASQ). Grades III-IV PVH-IVH are associated with definite moderate to severe neurodevelopmental impairment in all domains compared with neonates who have no IVH as shown in many previous reports. However, there is a growing body of evidence that the long-term prognosis of preterm infants with severe PVH-IVH is more favourable than previously thought [25-27].

\section{Literature Review}

The details of search strategy to collect the required evidence of neurodevelopmental outcomes in preterm 
survivors with mild grades of IVH are illustrated in Table 3. The inclusion criteria included: 1) Studies which explored the relationship between PVH-IVH, and neurodevelopmental outcome reported at 18 months of corrected gestational age or later; 2) Studies in preterm infants less than 37 weeks of gestational age; 3) Articles in English language and human based studies; 4) And publication date after January 2000 reflecting relatively recent NICU practices.

\section{Data Collection and Analysis}

Based on the predetermined criteria of article selection, the electronic searches of the manuscript of the selected studies were investigated and reviewed for suitability of inclusion. The following data were extracted from each study: The authors, publication year, study design, methods, study population, risk of bias, follow up timing, the developmental outcome definitions, completeness of data at follow up, and applicability. For this review, we designed a modified Cochrane data collection form (Appendix 1) that was used for data extraction and management.

\section{Study quality assessment}

The selected articles were examined for the relevance to the posted purpose and were evaluated by means of a quality assessment tool, The Modified Newcastle-Ottawa Scale for cohort studies (NOS) [28]. NOS was developed by the University of Newcastle (Australia) and the University of Ottawa (Canada) for the assessment of the non-randomised trials included in systematic reviews. The scale consists of eight questions about the cohort selection, the comparability, and the assessment of the outcome. The initial database search identified 1650 articles using the mentioned keywords. After removal of duplicates and analysis of the title and abstracts, 29 potentially relevant citations were found to match the inclusion criteria. Twenty articles were excluded after revision of the full-text articles, and 9 articles were selected for inclusion (Figure 4). Variables of the selected studies including authors, population characteristics, control characteristics, age of assessment and follow up rates, primary objectives, and neurodevelopmental outcomes are illustrated in Table 4.

\section{Impact of Lower Grades IVH on Neurodevel- opmental Outcome}

The impact of mild PVH-IVH on the neurodevelopmental outcomes remains elusive. As illustrated in Table 4, Some studies showed significant neurodevelopmental disabilities, $\mathrm{CP}$ and cognitive/language impairments in preterm infants with mild PVH-IVH compared to infants without IVH [29-33]. Other studies refuted any significant long-term neurodevelopmental disabilities with mild grades $\mathrm{PVH}-\mathrm{IVH}$ particularly those utilised MRI as an adjuvant neuroimaging modality [34-37]. The

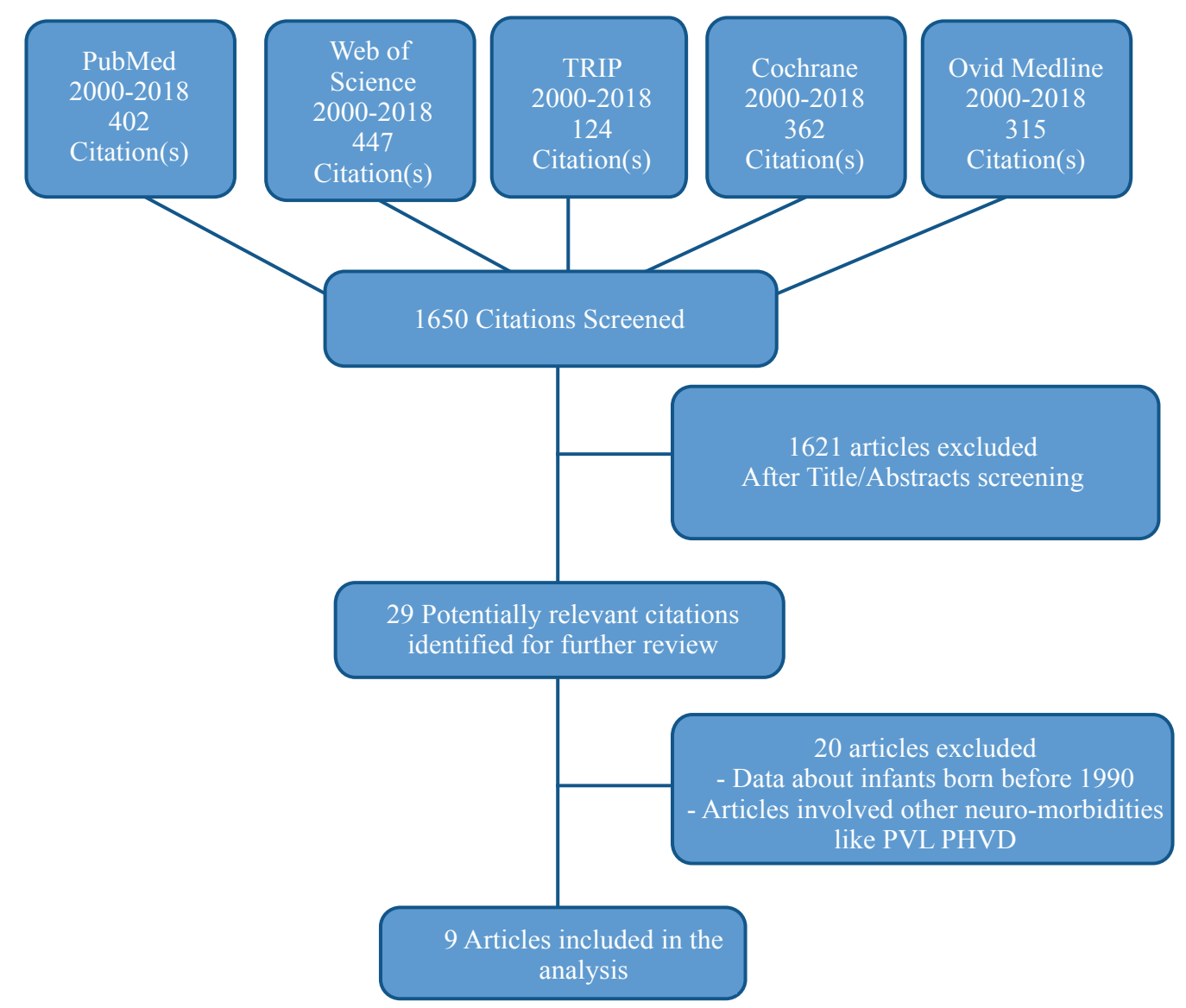

Figure 4: Flow diagram of study selection process. 
Table 4: Summary of the selected trials on neurodevelopmental outcome following IVH grades I-II.

\begin{tabular}{|c|c|c|c|c|c|}
\hline Authors & $\begin{array}{l}\text { Study } \\
\text { population }\end{array}$ & $\begin{array}{l}\text { Controls with } \\
\text { Normal cUS }\end{array}$ & $\begin{array}{l}\text { Age of } \\
\text { assessment } \\
\text { and follow up } \\
\text { rate }\end{array}$ & $\begin{array}{l}\text { Primary } \\
\text { objective }\end{array}$ & $\begin{array}{l}\text { Neurodevelopmental } \\
\text { outcomes }\end{array}$ \\
\hline $\begin{array}{l}\text { Sherlock, et al. } \\
2005 \text { [34] }\end{array}$ & $\begin{array}{l}\mathrm{PT}<28 \mathrm{w} . \\
\text { and or ELBW. } \\
\mathrm{n}=72\end{array}$ & $\begin{array}{l}\mathrm{PT}<28 \mathrm{w} . \\
\text { and or ELBW. } \\
\mathrm{n}=180\end{array}$ & $\begin{array}{l}-8 \text { y. } \\
\text {-Follow up: } \\
90.6 \%\end{array}$ & $\begin{array}{l}\text {-CP } \\
\text {-Neurosensory disability } \\
\text {-Cognitive and educational } \\
\text { outcome }\end{array}$ & $\begin{array}{l}\text {-CP in controls: } 6.7 \% \text { Vs. } \\
6.4 \% \text { in GI and } 24 \% \text { in GII. } \\
\text {-Cognitive functions of } \\
\text { infants with grade I, II were } \\
\text { like those with no IVH. }\end{array}$ \\
\hline $\begin{array}{l}\text { Patra, et al. } 2006 \\
\text { [31] }\end{array}$ & $\begin{array}{l}\text { ELBW. } \\
n=104\end{array}$ & $\begin{array}{l}\text { ELBW. } \\
n=258\end{array}$ & $\begin{array}{l}-20 \text { m. } \\
\text {-Follow up: } \\
91 \%\end{array}$ & $\begin{array}{l}\text { - CP, } \\
\text { neurodevelopmental } \\
\text { impairment, } \\
\text {-unilateral or bilateral } \\
\text { blindness and deafness at } \\
\text { 20months. }\end{array}$ & $\begin{array}{l}\text {-CP in GI-II IVH: } 8 \% \text {. No } \\
\text { IVH: } 3 \% \text {. } \\
\text {-MDI in GI-II IVH: } 45 \% \text {. No } \\
\text { IVH: } 25 \% \\
\text {-Major neurogenic } \\
\text { abnormality: } 13 \% \text { vs. } 5 \% \text { in } \\
\text { no IVH. }\end{array}$ \\
\hline $\begin{array}{l}\text { Futagi, et al. } 2006 \\
\text { [33] }\end{array}$ & $\begin{array}{l}\text { Mean GA } \\
28.1 \mathrm{w} \\
\mathrm{n}=381\end{array}$ & No control & $\begin{array}{l}-1.5,3, \text { and } \\
6 y . \\
\text {-Follow-up: } \\
58.2 \%\end{array}$ & $\begin{array}{l}\text {-Mortality } \\
\text { Neurodevelopmental } \\
\text { outcome (Normal, CP, MR) } \\
\text {-Neurosensory impairment } \\
\text { and epilepsy. }\end{array}$ & $\begin{array}{l}\text {-CP in GI: } 7.2 \%, \text { GII: } \\
17.3 \% \\
\text {-Epilepsy in GI: } 4.8 \% \text { and } \\
\text { in GII: } 5.3 \% \text {. } \\
\text {-No significant difference } \\
\text { in subtypes and severity } \\
\text { of CP among different IVH } \\
\text { grades. }\end{array}$ \\
\hline $\begin{array}{l}\text { Klebermass- } \\
\text { Schrehof, et al. } \\
2012 \text { [29] }\end{array}$ & $\begin{array}{l}\text { PT }<32 w . \\
n=121\end{array}$ & $\begin{array}{l}\text { PT }<32 w . \\
n=287\end{array}$ & $\begin{array}{l}-1,2,3 \text {, and } 5 y . \\
\text {-Follow up: } \\
61 \%\end{array}$ & $\begin{array}{l}\text { Neurodevelopmental } \\
\text { outcome at } 1,2,3 \text {, and } 5 \\
\text { years. } \\
\text {-CP, visual and acoustic } \\
\text { impairment. }\end{array}$ & $\begin{array}{l}\text {-CP in controls } 14.3 \% \text { Vs. } \\
38.4 \% \text { in } \mathrm{Gl} \text {, and } 55 \% \text { in } \\
\text { GII. } \\
\text {-Significant NDI in PT < } 28 \\
\text { w with all grades of IVH } \\
\text { compared to PT > } 28 \mathrm{~W} \text {. }\end{array}$ \\
\hline $\begin{array}{l}\text { Payne et, al. } 2013 \\
\text { [36] }\end{array}$ & $\begin{array}{l}\text { PT }<27 w . \\
n=270\end{array}$ & $\begin{array}{l}\text { PT }<27 w . \\
n=1021\end{array}$ & $\begin{array}{l}-18-22-m . \\
\text {-Follow up: } \\
87 \%\end{array}$ & $\begin{array}{l}\text {-CP } \\
\text {-Gross motor functional } \\
\text { limitation. } \\
\text {-Composite NDI (moderate } \\
\text { to severe CP, severe visual } \\
\text { impairment, deafness, or } \\
\text { cognitive score }<70 \text {.) }\end{array}$ & $\begin{array}{l}\text {-No significant differences } \\
\text { in the neurodevelopmental } \\
\text { outcome among PT infants } \\
\text { with GI-II IVH and those } \\
\text { without IVH at } 18-22 \\
\text { months CA. (CP in GI-II: } \\
9 \% \text { Vs. } 8 \% \text { in no IVH). }\end{array}$ \\
\hline $\begin{array}{l}\text { Bolisetty, et al. } \\
2014 \text { [30] }\end{array}$ & $\begin{array}{l}\mathrm{PT}<28 \mathrm{w} . \\
\mathrm{n}=336\end{array}$ & $\begin{array}{l}\text { PT <28w. } \\
n=1043\end{array}$ & $\begin{array}{l}-2-3 \text { y. } \\
\text {-Follow up: } \\
74.8 \%\end{array}$ & $\begin{array}{l}\text {-moderate to severe } \\
\text { neurosensory impairment at } \\
2 \text { to } 3 \text { years' corrected age } \\
\text { (NDI, CP, Deafness, } \\
\text { Blindness) }\end{array}$ & $\begin{array}{l}\text {-G I-II IVH had increased } \\
\text { rates of neurosensory } \\
\text { impairment ( } 22 \% \text { vs } \\
12.1 \%), \text { developmental } \\
\text { delay }(7.8 \% \text { vs } 3.4 \%) \text {, } \\
\text { CP }(10.4 \% \text { vs } 6.5 \%) \text {, and } \\
\text { deafness }(6.0 \% \text { vs } 2.3 \%) \\
\text { compared with the no IVH } \\
\text { group. }\end{array}$ \\
\hline $\begin{array}{l}\text { Vohr, et al. } 2014 \\
\text { [32] }\end{array}$ & $\begin{array}{l}\text { PT with BW: } \\
600-1250 \mathrm{~g} \text {. } \\
\mathrm{n}=75\end{array}$ & $\begin{array}{l}\text { PT with BW: } \\
600-1250 \text { g. } n \\
=251\end{array}$ & $\begin{array}{l}-16 \text { years } \\
\text { Adults } \\
\text {-Follow up: } \\
77 \%\end{array}$ & $\begin{array}{l}\text {-Neurocognitive,languageand } \\
\text { intellectual abilities } \\
\text {-CP and neurosensory } \\
\text { impairment. }\end{array}$ & $\begin{array}{l}\text {-CP in GI: } 13.7 \% \text {, GII: } \\
15.1 \% \text {. Vs. } 6.7 \% \text { in no IVH } \\
\text { PT controls and none in } \\
\text { term controls. } \\
\text {-Preterm adolescents } \\
\text { with isolated GII IVH have } \\
\text { greater impairments of } \\
\text { cognitive and executive } \\
\text { functions compared to } \\
\text { preterm adolescents with } \\
\text { G I or no IVH. }\end{array}$ \\
\hline
\end{tabular}




\begin{tabular}{|l|l|l|l|l|l|}
\hline $\begin{array}{l}\text { Ann Wy, et al. } \\
\text { 2015 [35] }\end{array}$ & LBW. $n=99$. & LBW. $n=291$ & $\begin{array}{l}-3-18 \\
\text { y. -Follow } \\
\text { up:71.3\% }\end{array}$ & $\begin{array}{l}\text {-Cognitive functioning at } \\
3,8,18 \text { years. } \\
\text {-Behaviour and academic } \\
\text { achievements at 8,18 years }\end{array}$ & $\begin{array}{l}\text {-No significant adverse } \\
\text { neurobehavioral sequalae } \\
\text { were observed at 3, 8, and } \\
18 \text { years of age among } \\
\text { survivors with G1-II IVH. }\end{array}$ \\
\hline $\begin{array}{l}\text { Reubsaet, et al. } \\
\mathbf{2 0 1 7}[37]\end{array}$ & $\mathrm{PT}: 24-32 \mathrm{w}$. & $\mathrm{PT}: 24-32 \mathrm{w}$. & $-18-30-\mathrm{m}$. & $-\mathrm{CP}$ & $\begin{array}{l}\text {-Similar early } \\
\text { neurodevelopmental } \\
\text { outcomes between preterm } \\
\text { infants with low grade IVH } \\
\text { and matched controls with } \\
\text { no IVH. (CP in GI-II: 9\% } \\
\text { Vs. 9\% in no IVH) }\end{array}$ \\
\hline
\end{tabular}

MDI: Mental Developmental Index; ELBW: Extreme Low Birth Weight; CP: Cerebral Palsy; PT: Preterm; CA: Corrected Age; NDI: neurodevelopmental Impairment.

conflicting results of these studies should be interpreted cautiously in view of different methodological limitations, cohort definition, evaluation methods, and the understanding of the developmental outcomes in each study. Furthermore, This may be explained by the bias in recruitment of preterm infants with low grade IVH who were evaluated solely with cranial ultrasound (cUS). Diffuse white matter injury (WMI) is commonly associated with $\mathrm{PVH}-\mathrm{IVH}$, even with the milder grades, hence, it potentially impairs cognitive, sensory and motor function development in premature infants $[38,39]$. Behaviour and cognitive deficits may only manifest late and present beyond school age [40]. In ELBW infants, Grade I-II PVH-IVH with no documented white matter injury is not innocent and is associated with moderate to severe neurosensory impairments, cerebral palsy, and deafness at 2-3 years corrected age $[20,30,41]$. A meta-analysis by Mukerji $A$, et al. [42] concluded that mild PVH-IVH was associated with higher odds of longterm moderate to severe neurodevelopmental impairment (NDI) but not cerebral palsy or cognitive delay at 18-24 months corrected age. It is obvious that studies assessed the neurodevelopmental outcomes at the age of 2-3 years by Klebermass, et al. [29], Bolisetty, et al. [30], and Patra, et al. [31] showed adverse neurodevelopmental outcomes compared to studies assessing the developmental outcomes at later age groups of 8 , and 18 years by Sherlock, et al. [34] and Ann Wye, et al. [35] respectively that denied measurable effects of mild IVH on neurocognitive outcomes. This can be explained by the fact that postnatal period from 16 months to 2.5 years is associated with characteristic differentiation and maturation of CNS. A rapid synaptogenesis, myelination, and dendritic growth spurts occur in a high rate followed by a process of selective refinement giving a chance to the environmental factors to influence CNS structures [43]. The initial overproduction of synapses in this period provides a room for potential neuronal recovery after initial early brain insult [44]. The neurodevelopmental milestones acquisition is a dynamic process and not merely dependent on the perinatal period, despite its major impact, but represents complicated multifactorial processes. Other interacting factors such as environmental, social, and demographic characteris- tics of the families would greatly influence the eventual developmental outcome of preterm infants [45]. Maternal parity, education, age, Ethnity, medical insurance, and marital status are among the sociodemographic variables that correlate with cognitive outcomes of preterm infants. It seems that parental sociodemographic factors are not only important determinants of the occurrence of PVH-IVH, but also play a significant role in the long-term neurodevelopmental outcome among IVH survivors. Sociodemographic factors should be considered as a 'continuum' with an extended influence starting at the prenatal period of critical neuronal proliferation, migration and synaptogenesis, and then progressing into the postnatal period, adolescence, and early adulthood.

\section{Neuroplasticity and Age of Neurodevelopmen- tal Assessment}

The issue of neurologic plasticity versus vulnerability and the possible recovery of neurologic insults even in later age should be considered when it comes to the long-term neurodevelopmental dynamic outcomes. Plasticity is the flexible and dynamic capacity of the central nervous system in early life to adapt in response to environmental stimuli through establishment of new neural connections $[46,47]$. This maybe a useful property in view of minimal functional specificity of the immature brain and the possible transfer of a function form a damaged area to another unaffected area [48]. This school is opposed by the immature brain vulnerability in face of different environmental, constitutional, and brain injury related factors. Hence, assessing the developmental outcome at a specific age and then generalising the outcome of certain grade of IVH is not fair. This observation is obvious in this review and may explain the conflicting developmental outcomes among survivors of mild PVH-IVH. Furthermore, the general intelligence notion is disputed by the theory of fluid and crystallised intelligence ( $G f-G c$ theory), where the fluid part $G f$ represents the influence of biological factors such as IVH on intellectual outcomes where the crystallised part $G c$ represents the influence of education and other demographic factors [49]. The peak capacity of fluid and crystallised knowledge is reached by early adulthood, 
hence highlighting the importance of extended follow up of cognitive developmental assessment beyond the previously thought the critical ages of development [50].

\section{Role of Neuroimaging and Prognostication Di- lemma}

No doubt that even mild PVH-IVH can potentially interfere with the immature delicate physiological architecture of the germinal matrix and cerebral white matter. White matter injury (WMI) may result from hypoxic events that precede or concur with IVH or from the release of iron, a significant free radical, that impair the normal proliferation and migration of oligodendrocyte precursors. Uncomplicated cases of mild PVH-IVH are associated with significant impairment of cortical grey matter development when examined by brain MRI at term equivalent age (TEA) [51]. WMI maybe more important than IVH regarding the later neurodevelopmental outcome and maybe easily overlooked if only cUS is used without additional brain MRI for the evaluation of preterm infants with IVH. Tortora, et al. [19] used Advanced computational methods; the diffusion tensor imaging (DTI) modality to assess the early WM microstructures changes occurring in isolated mild PVH-IVH. They found distinct patterns of WMI that can be missed on conventional brain MRI and correlates with poor neurocognitive outcomes at 2-3 years corrected age. Accordingly, it is feasible from the pathological point of view- at least- to presume a spectrum of negative neurodevelopmental outcomes secondary to even subtle degrees of PVH-IVH.

\section{Conclusion}

Infants with moderate to severe IVH have a higher prevalence of neurodevelopmental handicaps than infants with low grade or no IVH. However, the neurodevelopmental outcomes among infants with lower grade $\mathrm{PVH}-\mathrm{IVH}$ remain uncertain. The inconsistencies in neurodevelopmental outcomes among preterm infants with low grade IVH gives a clue to a wider spectrum of microstructural cerebral injuries that may be overlooked by cUS. Concomitant diffuse white matter injury of the brain is a major determinant of the neurodevelopmental outcome and can be detected by the newer brain MRI technology which is highly predictive for future neurocognitive disabilities. PVH-IVH may represent just the tip of iceberg of underlying cortical and subcortical microstructural pathologies that delineate the future neurocognitive outcomes. Further efforts to adopt advanced neuroimaging techniques and new classification system of brain injuries accompanying PVH-IVH based on the actual neuronal damage and not merely on the size or extent of the bleed are paramount, thus enhancing the prognostication process and family counselling. It is crucial to establish robust databases relating the new neuroimaging classification and the unified neurodevelopmental assessment scores to the long-term functional outcomes as well as mortality prediction.

\section{Funding Source}

No specific support.

\section{Conflict of Interest and Financial Disclosure}

Dr. Alshafei has disclosed no financial relationships relevant to this article. This commentary does not contain a discussion of an unapproved/investigative use of a commercial product/device.

\section{References}

1. Levene $M$, de Vries $L$ (2009) Neonatal intracranial hemorrhage. In: Levene MI, Chervenak FA, Fetal and neonatal neurology and neurosurgery. ( $4^{\text {th }}$ edn), Churchill Livingstone, Elsevier, Edinburgh, 395-430.

2. Allen KA (2013) Treatment of intraventricular haemorrhages in premature infants: Where is the evidence? Adv Neonatal Care 13: 127-130.

3. Ballabh P (2014) Pathogenesis and Prevention of Intraventricular Hemorrhage. Clinics in Perinatology 41: 47-67.

4. Papile L, Burnstein J, Burnstein R, Koffler H (1978) Incidence and evolution of sub-ependymal and intraventricular hemorrhage: A study of infants with birth-weight less than 1500 g. J Pediatr 92: 529-534.

5. Volpe J (1995) Intracranial hemorrhage: Germinal matrix-intraventricular hemorrhage of the premature infant: Neurology of the Newborn. ( $3^{\text {rd }}$ edn), WB Saunders, Philadelphia.

6. Ballabh $P(2010)$ Intraventricular Hemorrhage in Premature Infants: Mechanism of Disease. Pediatr Res 67: 1-8.

7. Vergani P, Locatelli A, Doria V, Paterlini G, Pezzullo J (2004) Intraventricular hemorrhage and periventricular leukomalacia in Preterm Infants. J Obstetrics \& Gynecology 104: 225-231.

8. Volpe J (2008) Intracranial hemorrhage: Germinal matrix-intraventricular hemorrhage. In: Joseph J. Volpe, Neurology of the Newborn. ( $5^{\text {th }}$ edn), Saunders, Philadelphia, 517.

9. Ciambra G, Arachi S, Protano C, Cellitti R, Caoci S, et al. (2013) Accuracy of transcranial ultrasound in the detection of mild white matter lesions in new-borns. Neuroradiol J 26: 284-289.

10. Plaisier A, Raets M, Ecury-Goossen G, Govaert P, Feijen-Roon M, et al. (2015) Serial cranial ultrasonography or early MRI for detecting preterm brain injury? Arch Dis Child Fetal Neonatal Ed 100: 293-300.

11. Mirmiran M, Barnes P, Keller K, Constantinou JC, Fleisher $\mathrm{BE}$, et al. (2004) Neonatal brain magnetic resonance imaging before discharge is better than serial cranial ultrasound in predicting cerebral palsy in very low birth weight preterm infants. Pediatrics 114: 992-998.

12. Benders $M$, Kersbergen $K$, de Vries $L$ (2014) Neuroimaging of white matter injury, intraventricular and cerebellar hemorrhage. Clin Perinatol 41: 69-82.

13. Back SA (2014) Cerebral white and grey matter injury in new-borns: new insights into pathophysiology and management. Clin Perinatol 41: 1-24.

14. Morel B, Antoni G, Teglas JP, Bloch I, Adamsbaum C (2016) Neonatal brain MRI: how reliable is the radiologist's eye? Neuroradiology 58: 189-193.

15. Rose J, Cahill-Rowley K, Vassar R, Yeom KW, Stecher $X$, et al. (2015) Neonatal brain microstructure correlates 
of neurodevelopment and gait in preterm children 18-22 month of age: an MRI and DTI study. Pediatr Res 78: 700708.

16. Guo T, Duerden EG, Adams E, Chau V, Branson HM, et al. (2017) Quantitative assessment of white matter injury in preterm neonates: Association with outcomes. Neurology 88: 614-622.

17. Cheong JL, Thompson DK, Spittle AJ, Potter CR, Walsh JM, et al. (2016) Brain volumes at term-equivalent age are associated with 2-year neurodevelopment in moderate and late preterm children. J. Pediatr 174: 91-97.

18. Kim DY, Park HK, Kim NS, Hwang SJ, Lee HJ (2016) Neonatal diffusion tensor brain imaging predicts later motor outcome in preterm neonates with white matter abnormalities. Ital J Pediatr 42: 104.

19. Tortora D, Martinetti C, Severino M, Uccella S, Malova M, et al. (2017) The effects of mild germinal matrix-intraventricular haemorrhage on the developmental white matter microstructure of preterm neonates: a DTI study. Eur Radiol 28: 1157-1166.

20. Luque MJ, Tapia JL, Villarroel L, Marshall G, Musante G, et al. (2014) A risk prediction model for severe intraventricular hemorrhage in very low birth weight infants and the effect of prophylactic indomethacin. J Perinatol 34: 43-48.

21. Kinney H, Volpe JJ (2012). Modelling the encephalopathy of prematurity in animals: the important role of translational research. Neurol Res Int 2012: 1-17.

22. Christian EA, Jin DL, Attenello F, Wen T, Cen S, et al. (2016) Trends in hospitalization of preterm infants with intraventricular hemorrhage and hydrocephalus in the United States, 2000-2010. J Neurosurg Pediatr 17: 260-269.

23. Bayley N (2006) Bayley Scales of Infant and Toddler Development. Administration Manual, Psychorp, United States of America. $3^{\text {rd }}$ edn.

24. Ballot D, Potterton J, Chirwa T, Hilburn N, Cooper PA (2012) Developmental outcome of very low birth weight infants in a developing country. BMC Pediatrics 12.

25. O'Shea T, Kuban K, Allred E, Paneth N, Pagano M, et al. (2008) Neonatal cranial ultrasound lesions and developmental delays at 2 years of age among extremely low gestational age children. Pediatrics 122: E662-E669.

26. Kuban KC, Allred EN, O'Shea TM, Paneth N, Pagano M, et al. (2009) Cranial ultrasound lesions in the NICU predict cerebral palsy at age 2 years in children born at extremely low gestational age. J Child Neurol 24: 63-72.

27. Davis AS, Hintz SR, Goldstein RF, Ambalavanan N, Bann CM, et al. (2014) Outcomes of extremely preterm infants following severe intracranial haemorrhage. J Perinatol 34: 203-208.

28. Wells G, Shea B, O'Connell D, Peterson J, Welch V, et al (2013) The Newcastle-Ottawa Scale (NOS) for assessing the quality of nonrandomised studies in meta-analyses.

29. Klebermass-Schrehof K, Czaba C, Olischar M, Fuiko R, Waldhoer T, et al. (2012) Impact of low-grade intraventricular hemorrhage on long-term neurodevelopmental outcome in preterm infants. Childs Nerv Syst 28: 2085-2092.

30. Bolisetty S, Dhawan A, Abdel-Latif M, Bajuk B, Stack J, et al. (2014) Intraventricular Hemorrhage and Neurodevelopmental Outcomes in Extreme Preterm Infants. Pediatrics 133: $55-62$.

31. Patra K, Wilson-Costello D, Taylor HG, Mercuri-Minich N, Hack M (2006) Grades I-II intraventricular hemorrhage in extremely low birth weight infants: effects on neurodevelopment. J Pediatr 149: 169-173.

32. Vohr BR, Allan W, Katz KH, Schneider K, Tucker R, et al. (2014) Adolescents born prematurely with isolated grade 2 hemorrhage in the early 1990s face increased risks of learning challenges. Acta Paediatr 103: 1066-1071.

33. Futagi Y, Toribe Y, Ogawa K, Suzuki Y (2006) Neurodevelopmental outcome in children with intraventricular hemorrhage. Pediatr Neurol 34: 219-224.

34. Sherlock RL, Anderson PJ, Doyle LW, Victorian Infant Collaborative Study Group (2005) Neurodevelopmental sequelae of intraventricular hemorrhage at 8 years of age in a regional cohort of ELBW/very preterm infants. Early Hum Dev 81: 909-916.

35. Ann Wy P, Rettiganti M, Li J, Yap V, Barrett K, et al. (2015) Impact of intraventricular hemorrhage on cognitive and behavioural outcomes at 18 years of age in low birth weight preterm infants. J Perinatol 35: 511-515.

36. Payne AH, Hintz SR, Hibbs AM, Walsh MC, Vohr BR, et al. (2013) Neurodevelopmental outcomes of extremely low-gestational-age neonates with low-grade periventricular-intraventricular hemorrhage. JAMA Pediatr 167: 451459.

37. Reubsaet $P$, Brouwer AJ, van Haastert IC, Brouwer MJ, Koopman C, et al. (2017) The Impact of Low-Grade Germinal Matrix-Intraventricular Hemorrhage on Neurodevelopmental Outcome of Very Preterm Infants. Neonatology 112: $203-210$.

38. Woodward L, Clark C, Bora S, Inder T (2012) Neonatal white matter abnormalities an important predictor of neurocognitive outcome for very preterm children. PLoS One 7.

39. Gano D, Andersen SK, Partridge JC, Bonifacio SL, Xu D, et al. (2015) Diminished white matter injury over time in a cohort of premature newborns. J. Pediatr 166: 39-43.

40. Allin MP, Kontis D, Walshe M, Wyatt J, Barker GJ, et al. (2011)White matter and cognition in adults who were born preterm. PLoS One 6: e24525.

41. Ancel PY, Livinec F, Larroque B, Marret S, Arnaud C, et al. (2006) Cerebral palsy among very preterm children in relation to gestational age and neonatal ultrasound abnormalities: the EPIPAGE cohort study. Pediatrics 117: 828-835.

42. Mukerji A, Shah V, Shah PS (2015) Periventricular/Intraventricular Hemorrhage and Neurodevelopmental Outcomes: A Meta-analysis. Pediatrics 136: 1132-1143.

43. Uylings $H$ (2006) Development of the human cortex and the concept of 'critical' or 'sensitive' periods. In: Gullberg M, Inderfrey $\mathrm{P}$, Series in cognitive neuroscience and language learning and processing. Blackwell Publishing, Oxford, 5990 .

44. Kolb B, Gibb R, Gorny G (2000) Cortical plasticity and the development of behaviour after early frontal cortical injury. Dev Neuropsychol 18: 423-444.

45. Anderson V, Spencer M, Wood A (2011) Do children really recover better? Neuro-behavioural plasticity after early brain insult. Brain 134: 2197-2221.

46. Taupin P (2006) Adult neurogenesis and neuroplasticity. Restorat Neurol Neurosci 24: 9-15.

47. Kadis DS, lida K, Kerr EN, Logan WJ, McAndrews MP, et al. (2007) Intra-hemispheric reorganization of language in children with medically intractable epilepsy of the left hemisphere. J Int Neuropsychol Soc 13: 505-516. 
48. Oddy M (1993) Head injury during childhood. Neuropsychol Rehabil 3: 301-320.

49. Horn JL (1998) A basis for research on age differences in cognitive abilities. In: JJ McArdle, R Woodcock, Human cognitive abilities in theory and practice. Erlbaum, Mahwah, NJ, 57-92.

50. McArdle JJ, Ferrer-Caja E, Hamagami F, Woodcock RW
(2002) Comparative longitudinal structural analyses of the growth and decline of multiple intellectual abilities over the life span. Dev Psychol 38: 115-142.

51. Vasileiadis GT, Gelman N, Han VK, Williams LA, Mann R, et al. (2004) Uncomplicated intraventricular hemorrhage is followed by reduced cortical volume at near-term age. Pediatrics 114: e367-e372. 


\section{Appendix 1:}

\section{Data extraction Tool}

\section{General Information}

Review title or ID

Study ID

Reference details

Report author contact details

Study funding source

Possible conflicts of interest

\section{EligibilityEligibility criteria met?}

Study Characteristics

Review Inclusion Criteria

(Insert inclusion criteria for each characteristic as defined in the Protocol)

Participants

Types of outcome measures

Reason for exclusion
Primary outcome:

Secondary outcomes:

\section{DO NOT PROCEED IF STUDY EXCLUDED FROM REVIEW}

\section{Population}

Population description

(from which study participants are drawn)

Setting

(including location and social context)

Inclusion criteria

Exclusion criteria

Method/s of recruitment of participants

\section{Methods}

Aim of study

Start date

End date

Duration of follow up

\section{Risk of Bias assessment}

Blinding of participants and personnel

Blinding of outcome assessment

Incomplete outcome data

\section{Participants}

Total no. infants enrolled

Age

Sex

Race/Ethnity

Co-morbidities

\section{Outcomes/Results}

Outcome name/definition

Scales: upper and lower limits

Statistical methods used and appropriateness of these methods notes

\section{Applicability}

Does the study directly address the review question?

\section{Other information}

Key conclusions of study authors

References to other relevant studies 